\title{
Bandwidth Extension of a Printed Square Monopole Antenna Loaded with Periodic Parallel-Plate Lines
}

\author{
Linglong Meng, Weimin Wang, Ming Su, Jinchun Gao, and Yuanan Liu \\ Beijing Key Laboratory of Work Safety Intelligent Monitoring, School of Electronic Engineering, \\ Beijing University of Posts and Telecommunications, Beijing 100876, China \\ Correspondence should be addressed to Linglong Meng; linglongm@126.com
}

Received 15 November 2016; Revised 18 February 2017; Accepted 30 March 2017; Published 3 May 2017

Academic Editor: Paolo Baccarelli

Copyright (C) 2017 Linglong Meng et al. This is an open access article distributed under the Creative Commons Attribution License, which permits unrestricted use, distribution, and reproduction in any medium, provided the original work is properly cited.

\begin{abstract}
A novel wideband monopole antenna employing periodically loaded parallel-plate lines is presented in this paper. The proposed antenna consists of a main square patch, a rectangular ground plane, and a periodical structure which is printed on both sides of substrate. A strong electromagnetic coupling technique is used to design the element that enhances impedance bandwidth and decreases the side-lobe level throughout the effective bandwidth. The antenna achieves a wide impedance bandwidth of about $61.1 \%$ or ranging from 2.16 to $4.06 \mathrm{GHz}$, an omnidirectional far-field pattern, and a peak radiation gain of $2.37 \mathrm{dBi}$. Finally, the proposed antenna is analyzed and measured. The measured results show satisfactory performance and good agreement with the simulated results.
\end{abstract}

\section{Introduction}

Recently, the size of mobile devices has become smaller due to the development of modern wireless communication systems, and compact antennas with wide bandwidth and good omnidirectional radiation characteristics are needed [1] to satisfy the various demands for wireless services, such as simple feeding, low profile, and low manufacturing cost. The currently popular designs, which are suitable for the wireless local area network (WLAN: 2.4-2.484 GHz), mobile worldwide interoperability for microwave access (WiMAX: 2.5-2.69 GHz, and 3.4-3.69 GHz), and S-band satellite communication service $(2-4 \mathrm{GHz})$, have been widely researched and used. Planar monopole antenna is a good candidate for wireless communication services because of its wide impedance bandwidth, omnidirectional radiation pattern, compact circuit structure, easy fabrication, and low cost [2]. In addition, printed monopole antennas are fabricated from a conventional monopole easily.

Most previous monopole antennas suffer from the protruded structure and the bulky size [3-10]. For instance, in [6], a circular disc monopole antenna has been proposed. The antenna presents a wide impedance bandwidth $(1.17-12 \mathrm{GHz})$. But this configuration is not entirely planar because of the large ground plane $\left(30 \times 30 \mathrm{~cm}^{2}\right)$. It cannot be integrated to the printed circuit board of the communication device. In [8], a planar monopole antenna with two plates that results in more than $5: 1$ bandwidth ratio is reported. Besides, studies on extending the bandwidth of monopole antennas have been widely investigated [11-17]. It has been reported that, by using different ground plane sizes, bandwidth can be increased to a substantial level [11]. For the $50 \times 50 \mathrm{~mm}^{2}$ ground plane, the measured bandwidth was $1.5 \mathrm{GHz}$, which represented a fractional impedance bandwidth of $58 \%$. In a circularly polarized printed monopole antenna using a lumped capacitor [12], the measured return loss bandwidth is raised to $60.5 \%(3.75-7 \mathrm{GHz})$. The antenna presented in [13] uses a truncated optimum ground plane for achieving wide bandwidth. In [16], a meandered-microstrip fed circular shaped monopole antenna is designed. Due to meanderedmicrostrip structure, the impedance bandwidth is extended. However, these design solutions are generally bulky, which may be not compatible with the new generation of wireless communication systems.

What is more, a novel approach to enhance the impedance bandwidth is reported by loading a trapezoid conductor-backed plane in [17]. The parasitic element is usually placed vertically under the upper radiating patch 


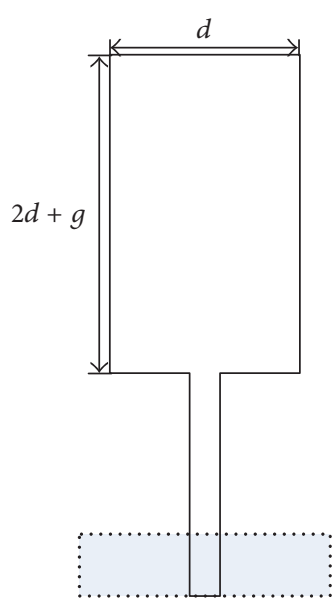

Antenna 1

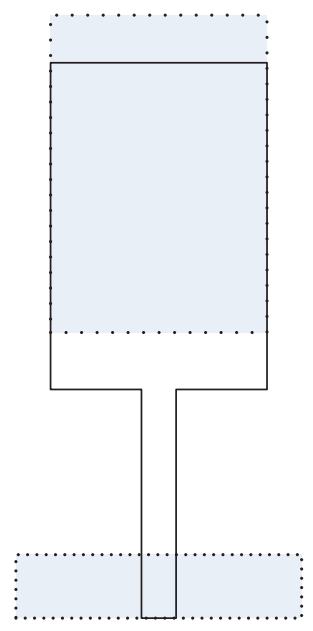

Antenna 3

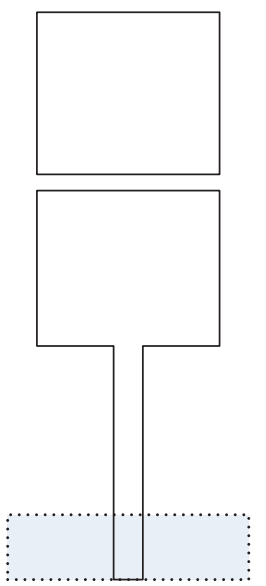

Antenna 2

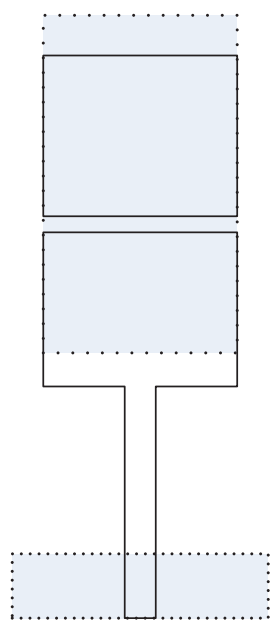

Antenna 4

Figure 1: Antenna geometry evolution for the proposed design.

so as to improve the impedance bandwidth. According to the principle, the original broadband antenna is achieved by loading a gap and a rectangular conductor-backed plane.

In this paper, a novel printed broadband monopole antenna is proposed and designed for wireless communication systems that can support the WLAN/WiMAX applications. The proposed structure consists of a main square patch, a rectangular ground plane, and a periodical structure which is printed on both sides of substrate. The wideband monopole antenna $(2.16-4.06 \mathrm{GHz})$ can be achieved, and the impedance performance has been largely improved due to the strong electromagnetic coupling between the monopole and the periodical structure. Simulation and experimental results of the prototyped antenna are presented and discussed.

\section{Design and Analysis}

2.1. Novel Broadband Monopole Antenna I. In this part, we present a miniaturized broadband monopole antenna with a gap and a parasitic planar square element. We know that planar printed monopole antennas are good candidates for use in different wireless communications because of their wide impedance bandwidth. The printed rectangular monopole has radiation pattern similar to that of a dipole antenna. Besides, it also possesses simple structure, planar configuration, and easy fabrication.

The antenna design evolution process to achieve broadband operation is shown in Figure 1. The proposed antenna (Ant. 4) is fabricated on the TLF-35A dielectric substrate of thickness $1.0 \mathrm{~mm}$, relative permittivity of 3.5 , and dielectric loss tangent of 0.0022 . The overall size of the proposed antenna is only $12.0 \mathrm{~mm} \times 39.5 \mathrm{~mm}$ or about $0.12 \lambda_{0} \times 0.39 \lambda_{0}$, where $\lambda_{0}$ is the free-space wavelength at the first resonant frequency $2.93 \mathrm{GHz}$.

The antenna design starts by a conventional rectangular monopole (Ant. 1). From Figure 2(a), it can be observed that, in this case, two resonant modes seem to form at about $2.86 \mathrm{GHz}$ and $6.15 \mathrm{GHz}$. However, the return loss is less than $10 \mathrm{~dB}$ at the first resonant frequency. More importantly, a wide operating frequency band $(4.14-6.67 \mathrm{GHz}$ or $46.8 \%)$ is obtained. In Figure 2(a), the antenna (Ant. 2) with a gap has a wide bandwidth from 4.46 to $6.64 \mathrm{GHz}(39.3 \%)$ for 


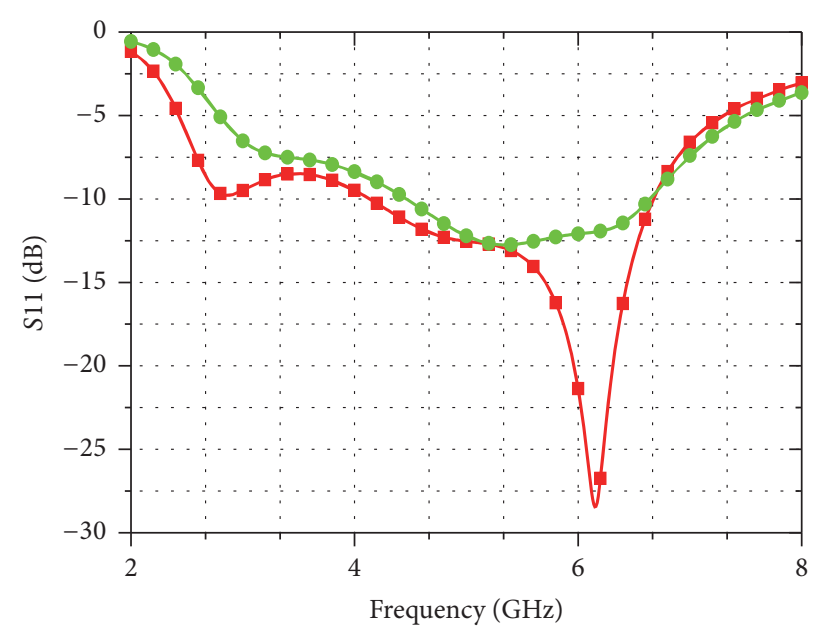

$\rightarrow$ Ant. 1

$\longrightarrow$ Ant. 2

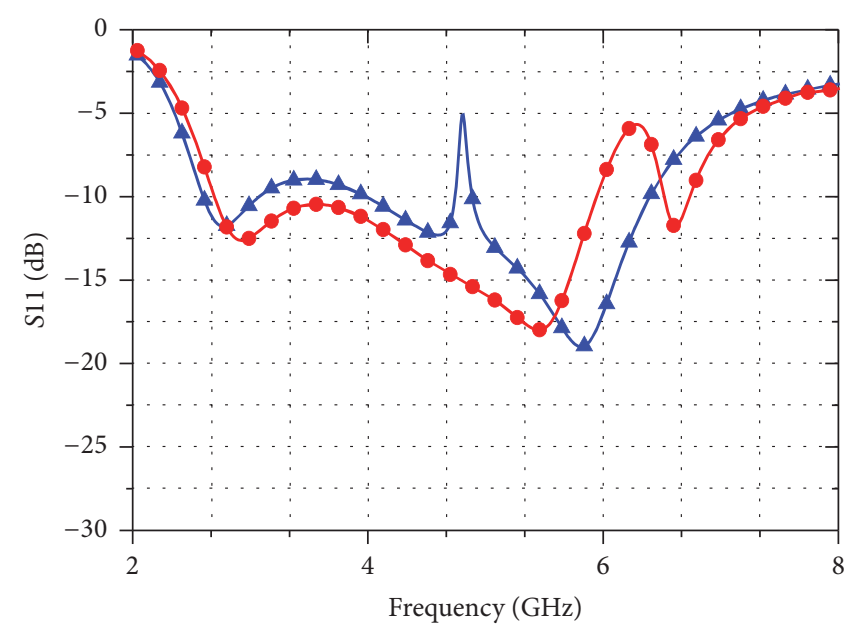

$\rightarrow$ Ant. 3

$\rightarrow$ Ant. 4

(a)

(b)

FIGURE 2: Simulated reflection coefficients of the proposed antenna.

VSWR $<2$. The gap can be seen when adding a series capacitance, but impedance matching is not good and the bandwidth does not increase relatively to Ant. 1. In [18], a broadband monopole antenna with a parasitic planar square element has been proposed. By adding a planar square conducting element, the impedance performance has been largely improved due to the strong electromagnetic coupling between the monopole and the parasitic element. So, tripleband characteristics of Ant. 3 are designed. However, this is not what we expect to be broadband. Finally, we present a miniaturized broadband monopole antenna (Ant. 4) with a gap and a parasitic planar rectangular element. As shown in Figure 2(b), a simulated VSWR of less than 2 has been realized across the $2.66-5.90 \mathrm{GHz}$ band (75.7\%).

Figure 3 shows the simulated radiation patterns at 2.88, 3.55 , and $5.43 \mathrm{GHz}$ in the $E$-plane (XOY-plane) and the $H$ plane (XOZ-plane), respectively. The $H$-plane patterns are almost omnidirectional in this operation frequency band. Radiation pattern for $E$-plane gives the bidirectional pattern at $3.55 \mathrm{GHz}$ frequency but appears more directional at 2.88 and $5.43 \mathrm{GHz}$.

2.2. Novel Broadband Monopole Antenna II. From Figure 3, it can be observed that the E-plane copolarization radiation patterns produce some side lobes due to current direction change. In order to obtain stable radiation patterns, a novel broadband printed square monopole antenna loaded with periodic parallel-plate lines is properly designed. The evolution of the proposed broadband antenna is shown in Figure 4, with the corresponding simulated reflection coefficients presented in Figure 5. As the number of parasitic planar square elements increases, the higher resonant frequency decreases, since the path of the antenna is increased. However, the lower resonant frequency has a little change.

Furthermore, it can be seen that when two unit cells (Ant. 5) are loaded to the monopole antenna, two resonances are separated from each other, giving two narrow bands.
While three unit cells were loaded, an enhanced impedance bandwidth of $61.1 \%$ ranging from 2.16 to $4.06 \mathrm{GHz}$ for $S 11$ $<-10 \mathrm{~dB}$ is achieved, and the size is $62.5 \times 12.0 \times 1.0 \mathrm{~mm}^{3}$. When four unit cells were loaded, a novel printed monopole antenna (Ant. 6) with dual wideband is presented. But the size of the antenna increased to $75.0 \times 12.0 \times 1.0 \mathrm{~mm}^{3}$. From the comparison, the three pluralities of periodically loaded parallel-plate lines achieve both broadband operation and compact size at the same time.

As a result of electromagnetic coupling, the plurality of periodically loaded aligned microstrip patches plays an important role in the broadband characteristics of this planar monopole. By adding the loading parallel-plate lines, the broadband monopole antenna is achieved.

\section{Antenna Geometry}

The configuration of the proposed antenna is shown in Figure 6(a), which is printed on a TLF-35A substrate with a relative dielectric constant of 3.5 , dielectric loss tangent of 0.0022 , and thickness of $1.0 \mathrm{~mm}$. The whole substrate occupies an area of $62.5 \times 12.0 \times 1.0 \mathrm{~mm}^{3}$, when the antenna and the ground plane are printed on different sides. The antenna can be treated as a printed square monopole with a periodical structure. It can be seen from Figure 6(b) that four square patches and microstrip feed line are printed on the top side of substrate. As shown in Figure 6(b), the feed line with a length of $l_{1}$ is connected to the coaxial cable through a $50 \Omega$ SMA connector. The square conducting plane on the top side of the substrate has a length of $d$, and $g$ is the gap between the square conducting planes on the same side of the substrate. In Figure 6(c), a rectangular ground plane and four square conducting planes under the microstrip line fed monopole antenna and three square conducting planes, respectively, are printed on the bottom side of the substrate. The antenna elements are simulated in ANSYS 

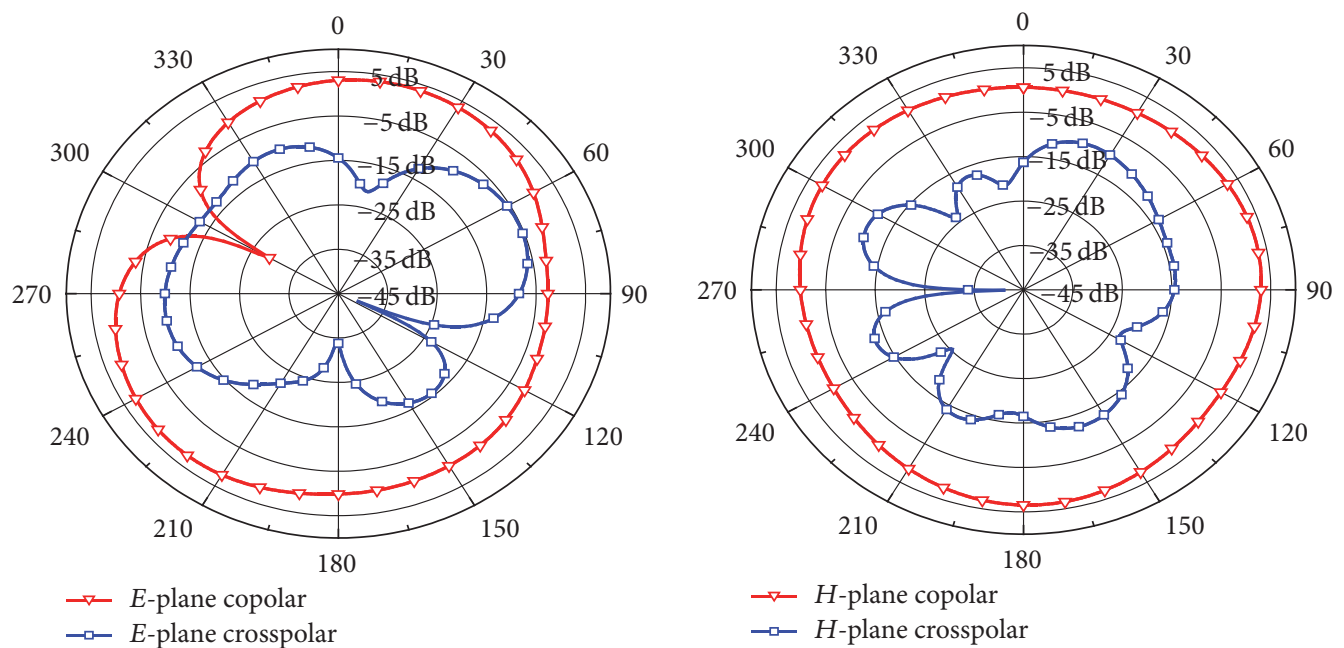

(a)
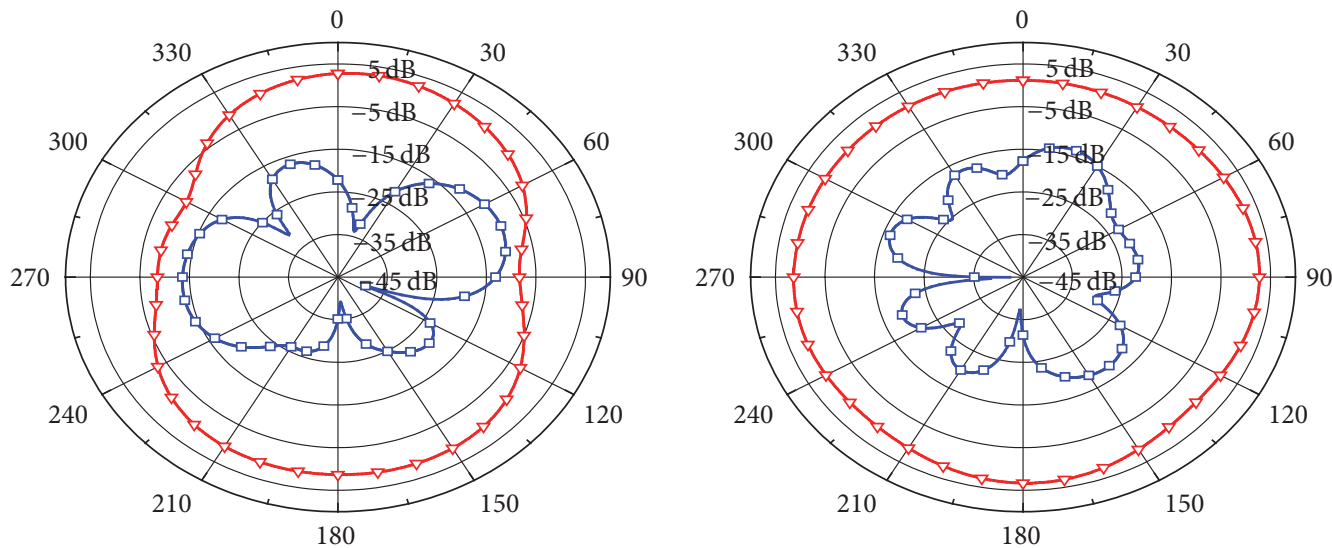

$\rightarrow-E$-plane copolar

$\multimap-E$-plane crosspolar

$\rightarrow \quad H$-plane copolar

$\multimap-H$-plane crosspolar

(b)

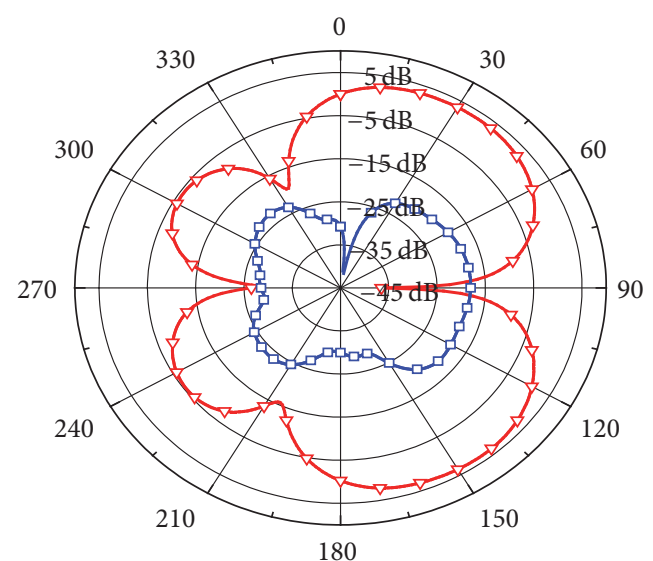

$\rightarrow$ E-plane copolar

$\neg-E$-plane crosspolar

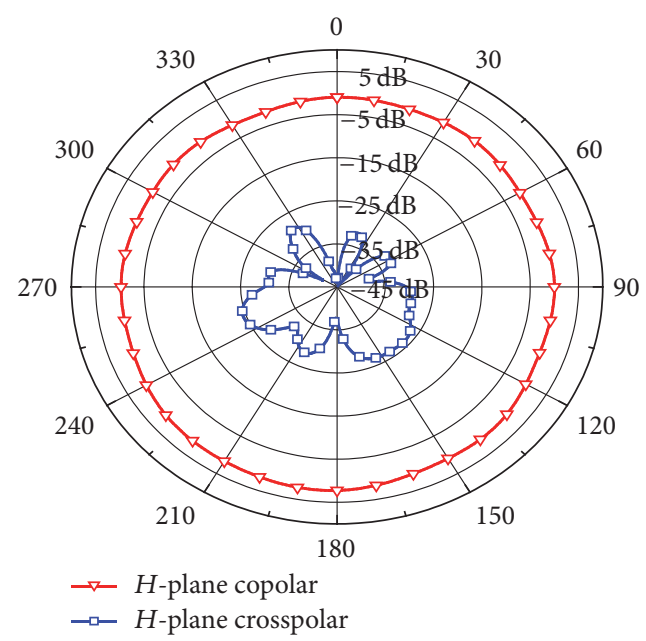

(c)

FIgURE 3: Simulated patterns (left: XOY-plane; right: XOZ-plane.) of the proposed Ant. 4 at (a) $2.88 \mathrm{GHz}$; (b) $3.55 \mathrm{GHz}$; (c) $5.43 \mathrm{GHz}$. 


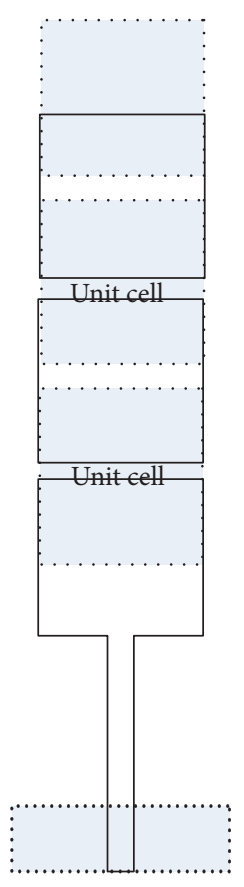

Antenna 5
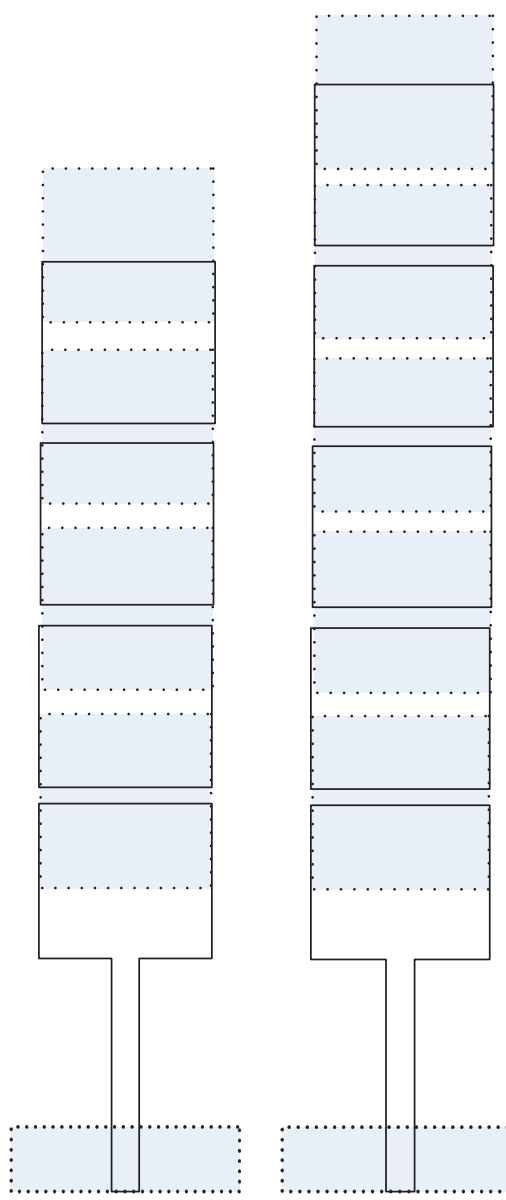

Proposed antenna
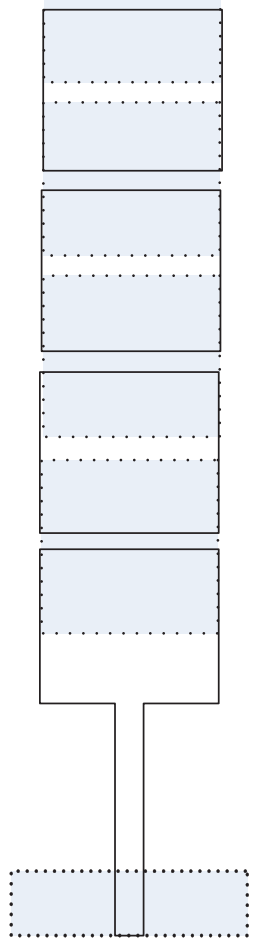

Antenna 6

FIGURE 4: Design evolution of the proposed antenna.

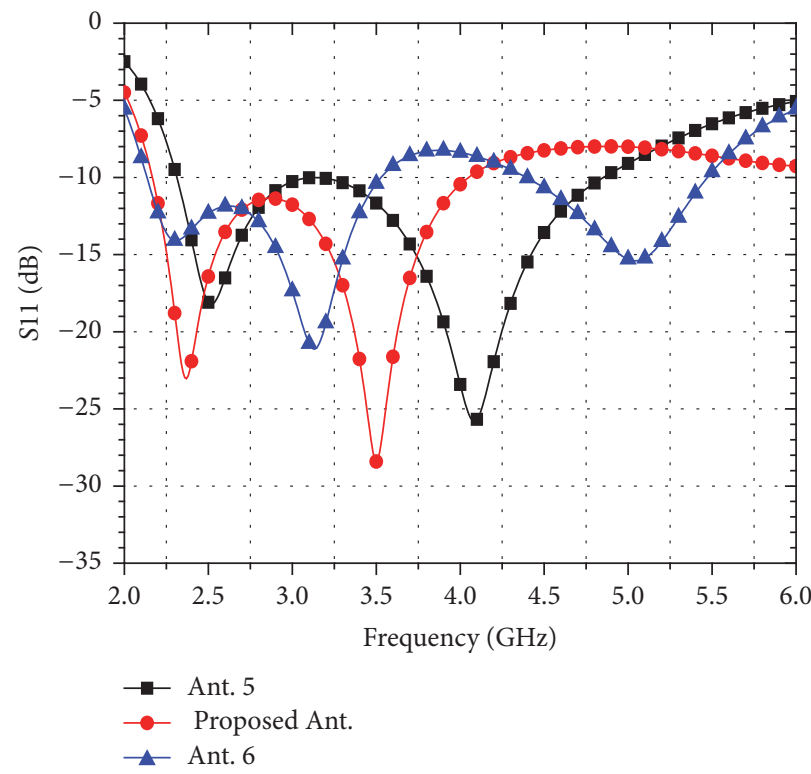

FIGURE 5: Simulated reflection coefficients of the different antenna. 


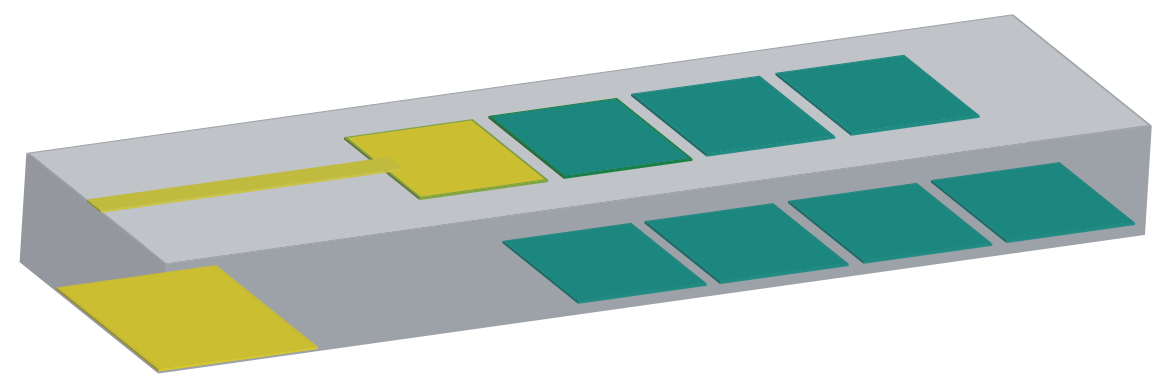

Monopole antenna

Periodical structure

(a)

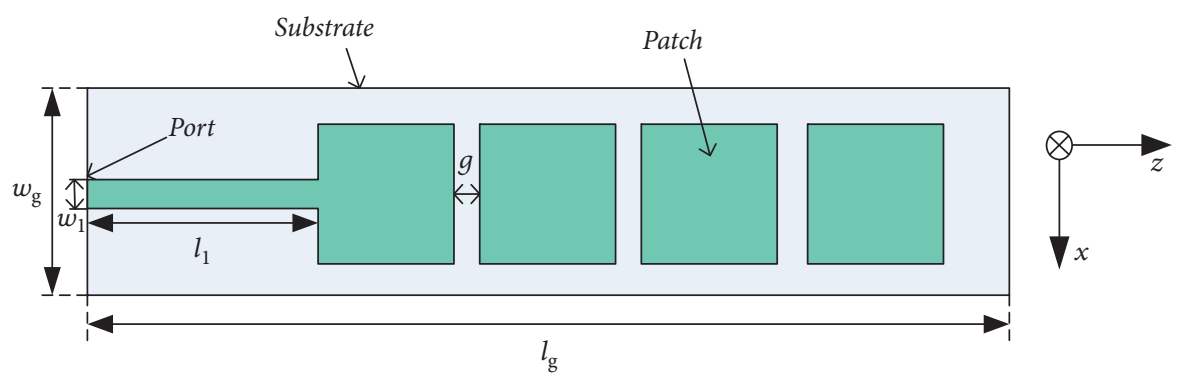

(b)

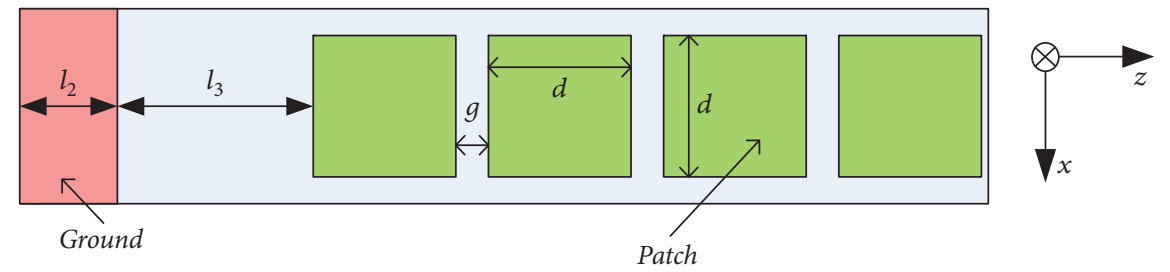

(c)

FIGURE 6: Geometry of monopole antenna. (a) 3D view; (b) top view; (c) bottom view.

TABLE 1: Values of key parameters.

\begin{tabular}{lc}
\hline Parameter & Value $(\mathrm{mm})$ \\
\hline$w_{g}$ & 12 \\
$l_{g}$ & 62.5 \\
$l_{1}$ & 16 \\
$l_{2}$ & 8 \\
$l_{3}$ & 13.25 \\
$l_{4}$ & 5.25 \\
$d$ & 10 \\
$h$ & 1 \\
$w_{1}$ & 1 \\
$g$ & 0.5 \\
\hline
\end{tabular}

HFSS full-wave simulator [19]. The optimized parameters of the antennas are given in Table 1.

\section{Simulation and Experimental Results}

Figure 7 shows different views of the fabricated prototype. The physical size of the wideband monopole antenna is

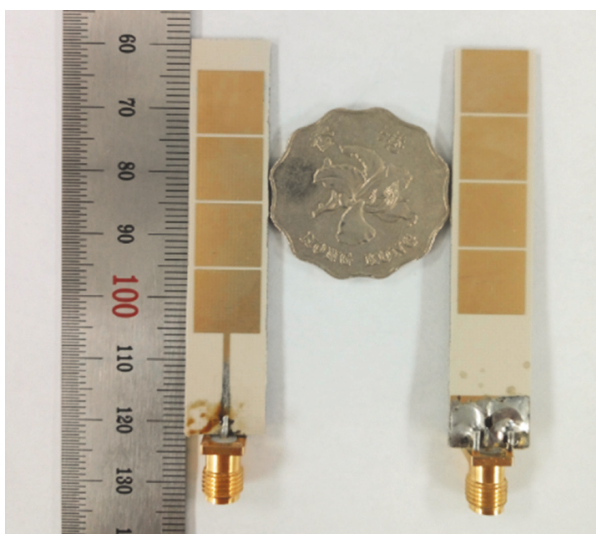

(a)

(b)

Figure 7: Photograph of the fabricated antenna. (a) Top view; (b) bottom view.

$62.5 \times 12.0 \times 1.0 \mathrm{~mm}^{3}$. Figure 8 shows the simulated and measured reflection coefficients of the proposed antenna. The simulated and measured results were obtained using 


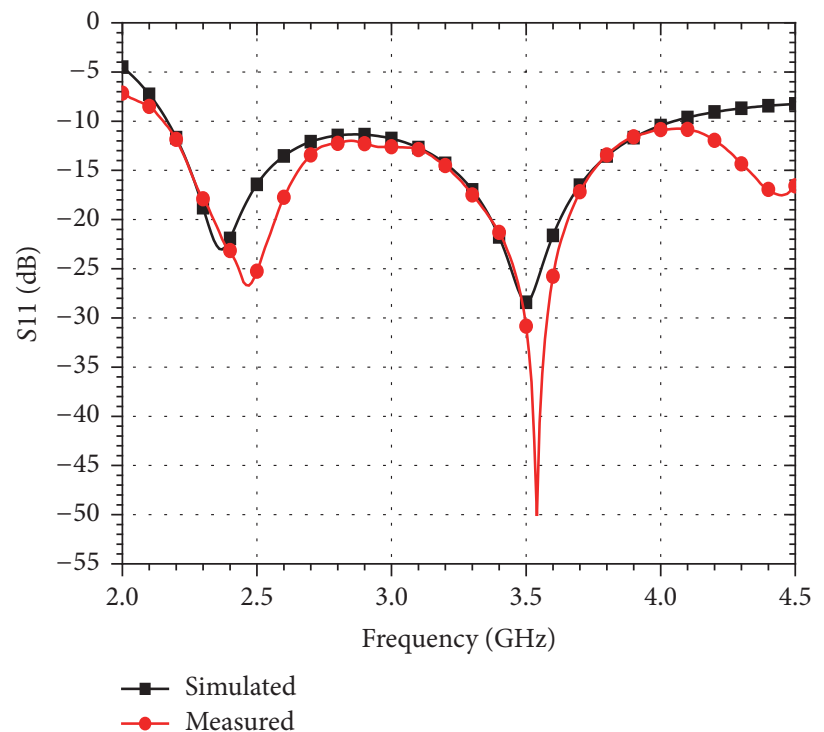

FIGURE 8: Simulated and measured reflection coefficients of the proposed antenna.
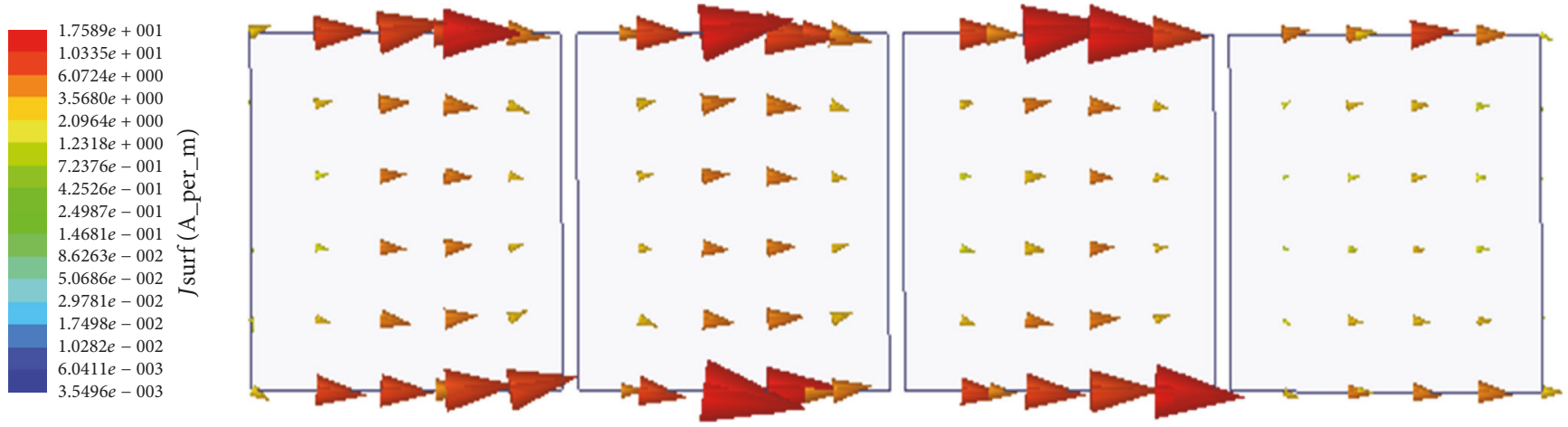

(a)
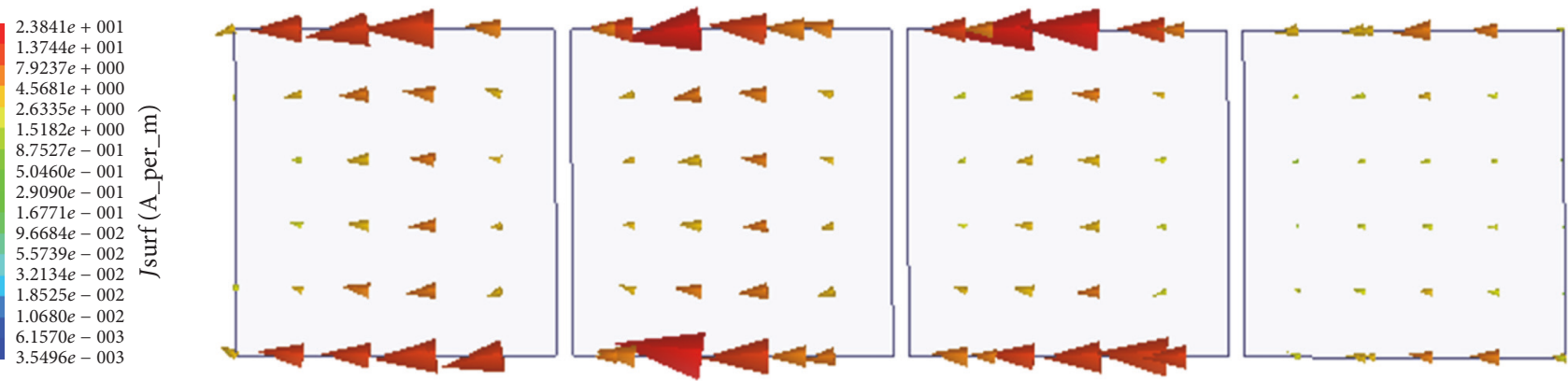

(b)

FigURE 9: Simulated surface currents distribution versus frequency. (a) $f=2.4 \mathrm{GHz}$; (b) $f=3.5 \mathrm{GHz}$.

ANSYS HFSS full-wave simulator [19] and Rohde \& Schwarz ZVA8 vector network analyzer, respectively. Also, it is evident that the impedance matching is excellent in intermediate frequencies as the matching bandwidth with $\operatorname{VSWR}<2$ is roughly $61.1 \%$ within frequency range of $2.16-4.06 \mathrm{GHz}$. The higher resonance frequency is almost no offset. Compatible with the fabrication tolerance, the lower resonance frequency has a slight frequency shift as shown in Figure 8.
The surface current distributions on the proposed antenna at $2.4 \mathrm{GHz}$ and $3.5 \mathrm{GHz}$ are shown in Figure 9. It is clear that the currents of the proposed monopole antenna remain almost in phase in Figures 9(a) and 9(b), respectively. Thus, good radiation patterns at $2.4 \mathrm{GHz}$ and $3.5 \mathrm{GHz}$ are achieved.

The measured radiation patterns in the $H$-plane $(x-y$ plane) and $E$-plane ( $x-z$ plane) at $2.4,3.0$, and $3.5 \mathrm{GHz}$ are plotted in Figure 10. A good radiation pattern is obtained 

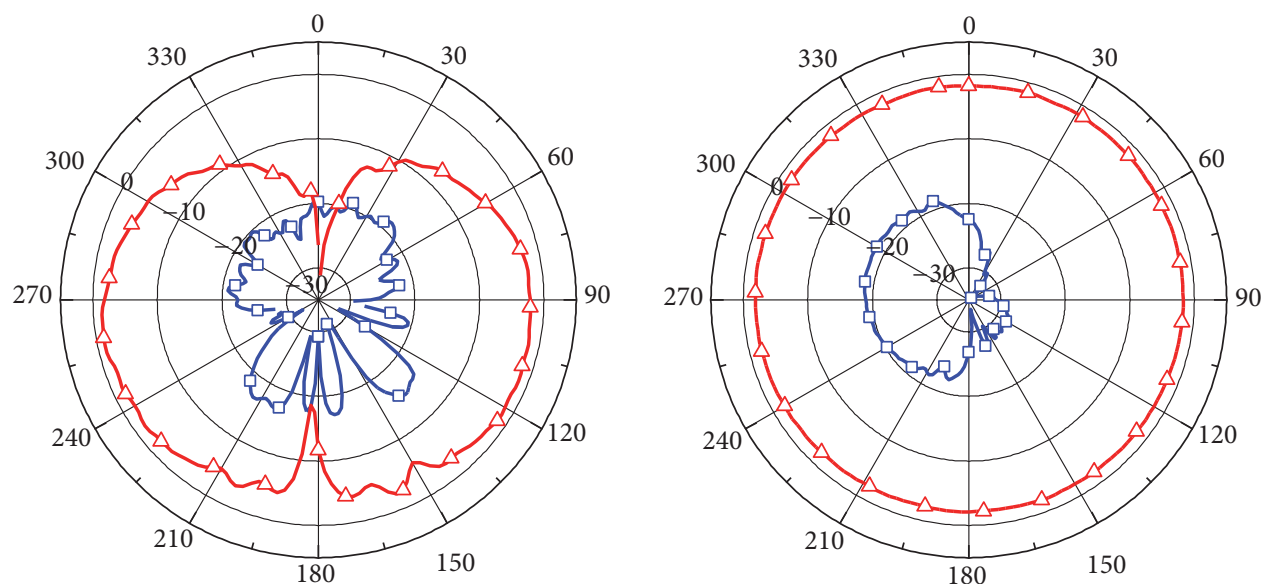

$\rightarrow-E$-plane crosspolar

$\rightarrow-H$-plane crosspolar

$\triangle-E$-plane copolar

$\neg-H$-plane copolar

(a)
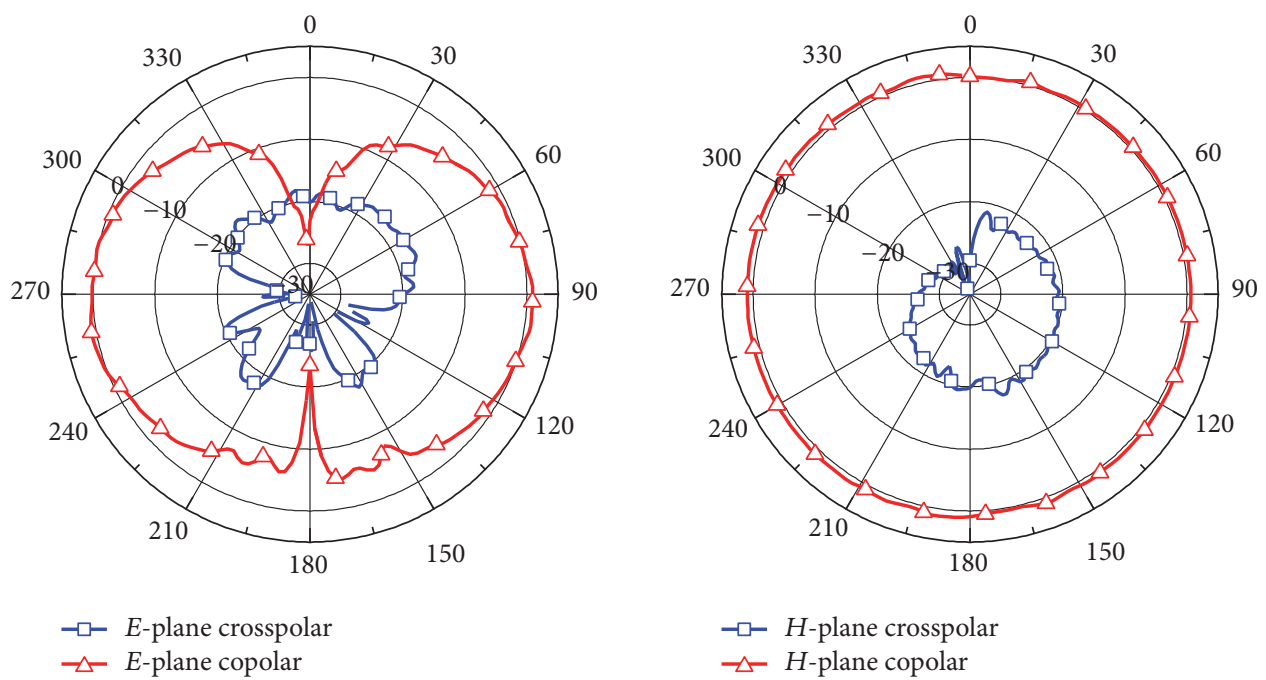

$\hookrightarrow-H$-plane crosspolar
$\neg-H$-plane copolar

(b)
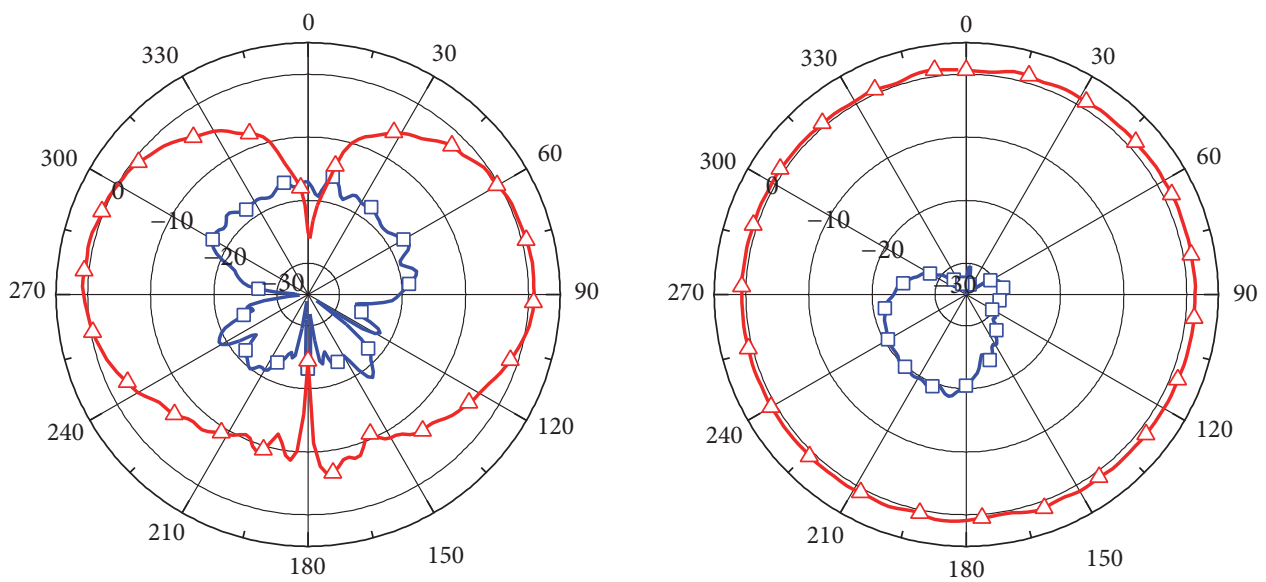

$\neg-E$-plane crosspolar

$\neg-H$-plane crosspolar

$\triangle-H$-plane copolar

(c)

FIGURE 10: Measured copolarization and cross-polarization of proposed antenna at different frequencies: (a) $2.4 \mathrm{GHz}$; (b) $3.0 \mathrm{GHz}$; and (c) $3.5 \mathrm{GHz}$ (left: $X O Z$-plane; right: $X O Y$-plane). 
TABLE 2: The performance of proposed antenna compared with other published antenna.

\begin{tabular}{lcccc}
\hline Reference & $|S 11|<-10 \mathrm{~dB}$ & Relative bandwidth & Antenna size & Relative dielectric constant \\
\hline$[12]$ & $3.75-7 \mathrm{GHz}$ & $60.5 \%$ & $52 \times 55 \times 1.52 \mathrm{~mm}^{3}$ & 2.2 \\
{$[14]$} & $5.1-6.05 \mathrm{GHz}$ & $17 \%$ & $24 \times 36 \times 1.6 \mathrm{~mm}^{3}$ & 4.4 \\
{$[20]$} & $1.85-3.40 \mathrm{GHz}$ & $59 \%$ & $150 \times 18 \times 1 \mathrm{~mm}^{3}$ & 2.65 \\
Proposed antenna & $2.16-4.06 \mathrm{GHz}$ & $61.1 \%$ & $62.5 \times 12 \times 1 \mathrm{~mm}^{3}$ & 3.5 \\
\hline
\end{tabular}

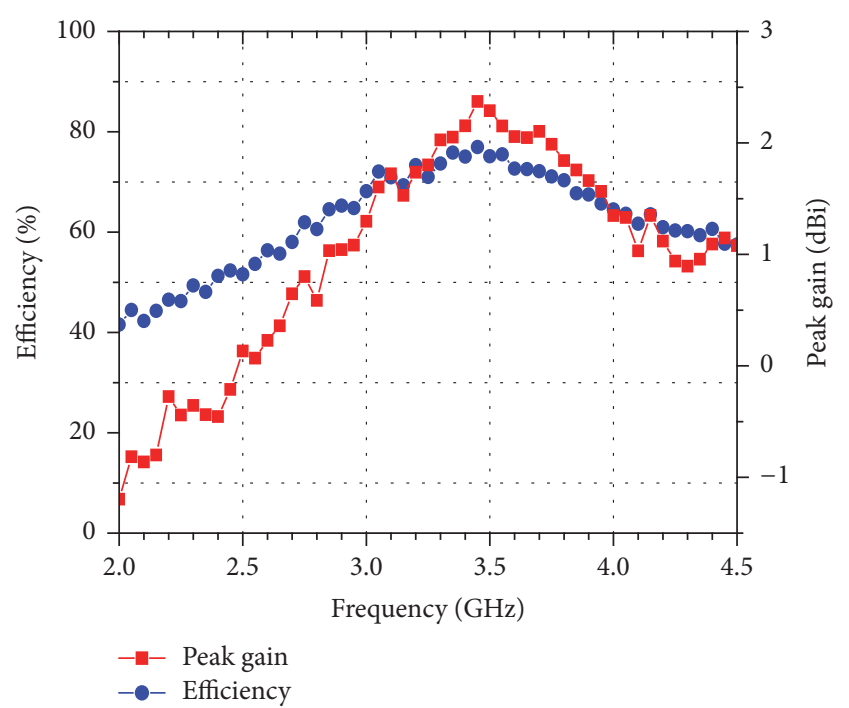

FIGURE 11: Measured peak gain and radiation efficiency of the proposed antenna.

in the $E$-plane and $H$-plane. From an overall view of these patterns, the antenna behaves quite similarly to the typical dipole antenna in the lower and higher frequency bands. The radiation patterns are stable throughout the wideband.

The measured peak gain of the proposed antenna is plotted in Figure 11 along with measured radiation efficiency of the proposed antenna. The measured peak gain of the proposed antenna varies from -0.86 to $2.37 \mathrm{dBi}$ within the effective bandwidth. The measured efficiency of the broadband antenna is above $46.5 \%$ at the operating band and about $75 \%$ peak efficiency at $3.5 \mathrm{GHz}$.

Table 2 shows the performance of proposed antenna compared with other published antenna. It can be seen that the proposed antenna occupies a small volume $(62.5 \times 12.0 \times$ $1.0 \mathrm{~mm}^{3}$ ) and obtains wide operating bandwidth (61.1\%). Finally, this table demonstrates the validity and practicability of the proposed method.

\section{Conclusion}

In this paper, a novel printed square wideband monopole antenna loaded with periodic parallel-plate lines is presented. The wideband enhancement of the antenna can be obtained by coupling between the monopole and the periodical structure. The measured $-10 \mathrm{~dB}$ impedance bandwidth is $1.90 \mathrm{GHz}$ from 2.16 to $4.06 \mathrm{GHz}$ (61.1\%), which covers WLAN (2.4-2.484 GHz), mobile WiMAX (2.5-2.69 GHz), WiMAX
(3.4-3.69 GHz), and $S$-band $(2-4 \mathrm{GHz})$ satellite communication service. The measured efficiency is higher than $46.5 \%$ within frequency bands. Good omnidirectional radiation performances are also obtained at the effective bandwidth. The structure of the proposed antenna is simple and easy to fabricate. The proposed antenna is suitable for the modern wireless communication systems.

\section{Conflicts of Interest}

The authors declare that there are no conflicts of interest regarding the publication of this paper.

\section{Acknowledgments}

This work was supported in part by National Key Basic Research Program of China (973 Program) (no. 2014CB339900) and National Natural Science Foundation of China for the Major Equipment Development (no. 61327806).

\section{References}

[1] C. Caloz and T. Itoh, Electromagnetic Metamaterials: Transmission Line Theory and Microwave Application, John Wiley \& Sons, New York, NY, USA, 2006.

[2] K. P. Ray and Y. Ranga, "Printed rectangular monopole antennas," in Proceedings of the IEEE Antennas and Propagation Society International Symposium (APS '06), pp. 1693-1696, July 2006.

[3] Z. N. Chen, "Broadband planar monopole antenna," IEE Proceedings: Microwaves, Antennas and Propagation, vol. 147, no. 6, pp. 526-528, 2000.

[4] K. P. Ray, P. V. Anob, R. Kapur, and G. Kumar, "Broadband planar rectangular monopole antennas," Microwave and Optical Technology Letters, vol. 28, no. 1, pp. 55-59, 2001.

[5] K.-L. Wong, S.-W. Su, and C.-L. Tang, "Broadband omnidirectional metal-plate monopole antenna," IEEE Transactions on Antennas and Propagation, vol. 53, no. 1, pp. 581-583, 2005.

[6] N. P. Agrawall, G. Kumar, and K. P. Ray, "Wide-band planar monopole antennas," IEEE Transactions on Antennas and Propagation, vol. 46, no. 2, pp. 294-295, 1998.

[7] M. Hammoud, P. Poey, and F. Colombel, "Matching the input impedance of a broadband disc monopole," Electronics Letters, vol. 29, no. 4, pp. 406-407, 1993.

[8] S. M. Mazinani and H. R. Hassani, "A novel broadband plateloaded planar monopole antenna," IEEE Antennas and Wireless Propagation Letters, vol. 8, pp. 1123-1126, 2009.

[9] K. Saraswat and A. R. Harish, "Split ring loaded monopole antenna," IET Microwaves, Antennas and Propagation, vol. 10, no. 4, pp. 420-425, 2016. 
[10] M. Li and K.-M. Luk, "A low-profile, low-backlobe and wideband complementary antenna for wireless application," IEEE Transactions on Antennas and Propagation, vol. 63, no. 1, pp. 714, 2015.

[11] M. J. Ammann and M. John, "Optimum design of the printed strip monopole," IEEE Antennas and Propagation Magazine, vol. 47, no. 6, pp. 59-61, 2005.

[12] T. V. Hoang, T. T. Le, and H. C. Park, "Bandwidth improvement of a circularly polarised printed monopole antenna using a lumped capacitor," Electronics Letters, vol. 52, no. 13, pp. 10911092, 2016.

[13] M. N. Suma, P. C. Bybi, and P. Mohanan, "A wideband printed monopole antenna for 2.4-GHz WLAN applications," Microwave and Optical Technology Letters, vol. 48, no. 5, pp. 871-873, 2006.

[14] S. Y. Shi, W. Q. Che, W. C. Yang, and Q. Xue, "Miniaturized patch antenna with enhanced bandwidth based on signal-interference feed," IEEE Antennas and Wireless Propagation Letters, vol. 14, pp. 281-284, 2015.

[15] R. Pandeeswari and S. Raghavan, "Broadband monopole antenna with split ring resonator loaded substrate for good impedance matching," Microwave and Optical Technology Letters, vol. 56, no. 10, pp. 2388-2392, 2014.

[16] M. R. Ahsan, M. T. Islam, M. H. Ullah, and N. Misran, "Bandwidth enhancement of a dual band planar monopole antenna using meandered microstrip feeding," The Scientific World Journal, vol. 2014, Article ID 856504, 8 pages, 2014.

[17] C.-Y. Pan, T.-S. Horng, W.-S. Chen, and C.-H. Huang, "Dual wideband printed monopole antenna for WLAN/WiMAX applications," IEEE Antennas and Wireless Propagation Letters, vol. 6, pp. 149-151, 2007.

[18] Z. N. Chen and Y. W. M. Chia, "Broadband monopole antenna with parasitic planar element," Microwave and Optical Technology Letters, vol. 27, no. 3, pp. 209-210, 2000.

[19] "High Frequency Structure Simulator (HFSS)," version 13, Ansoft Corporation.

[20] K. Wei, Z. Zhang, Z. Feng, and M. F. Iskander, "A wideband MNG-TL dipole antenna with stable radiation patterns," IEEE Transactions on Antennas and Propagation, vol. 61, no. 5, pp. 2418-2424, 2013. 


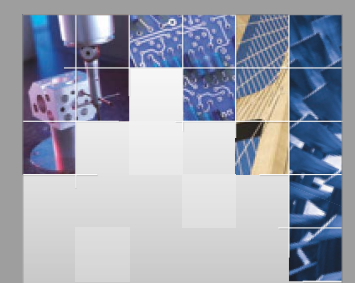

\section{Enfincering}
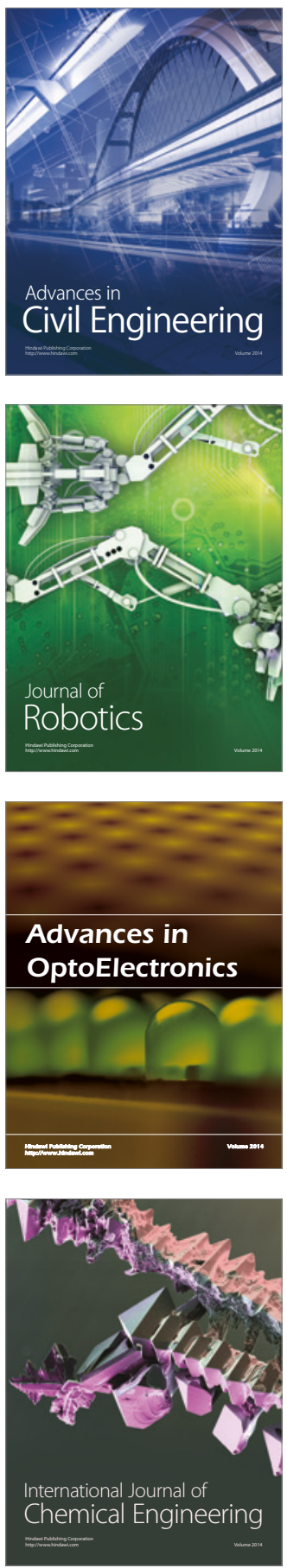

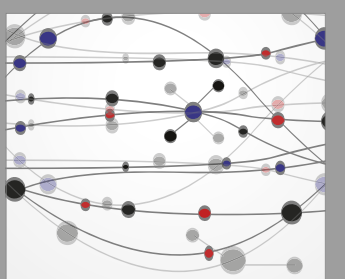

The Scientific World Journal

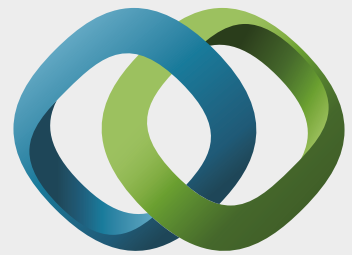

\section{Hindawi}

Submit your manuscripts at

https://www.hindawi.com
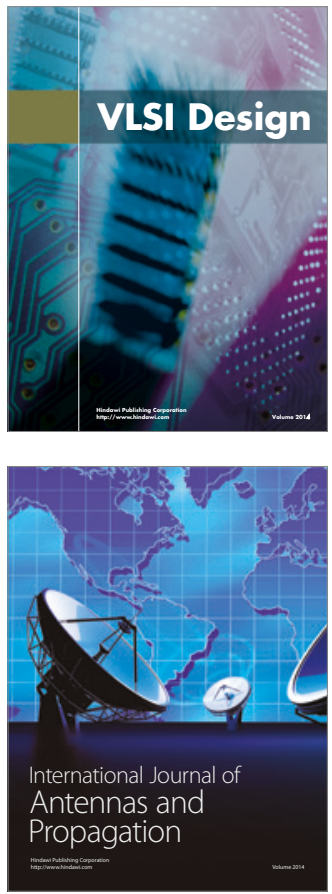

\section{Rotating}

Machinery
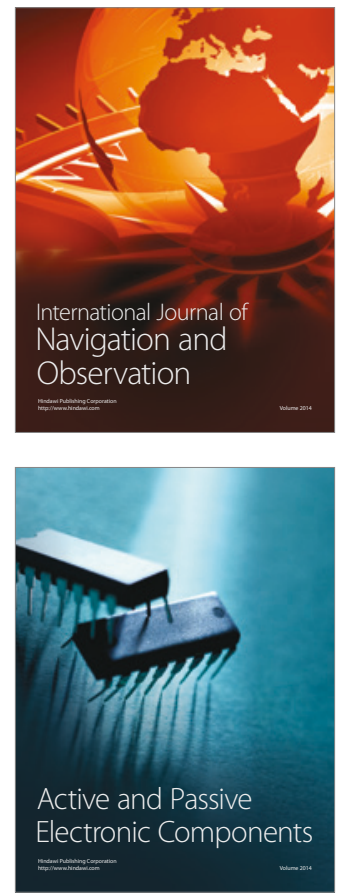
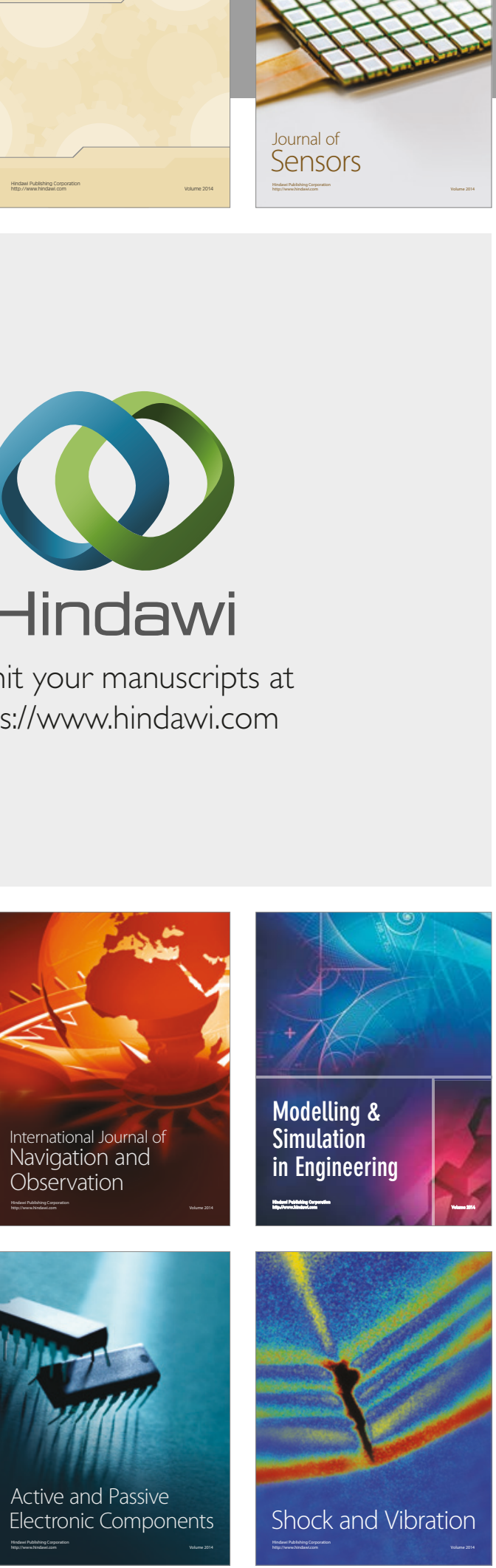
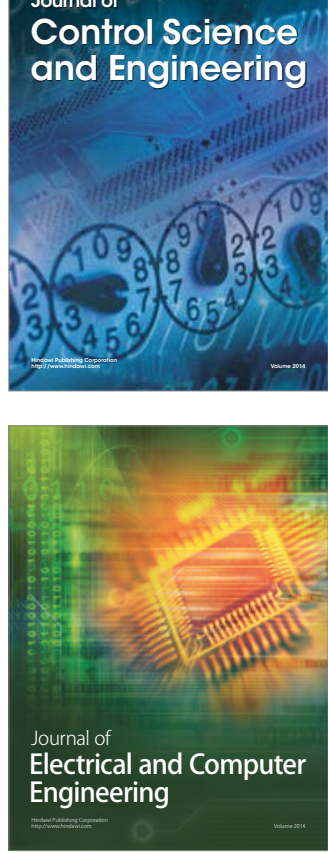

Distributed

Journal of

Control Science

and Engineering
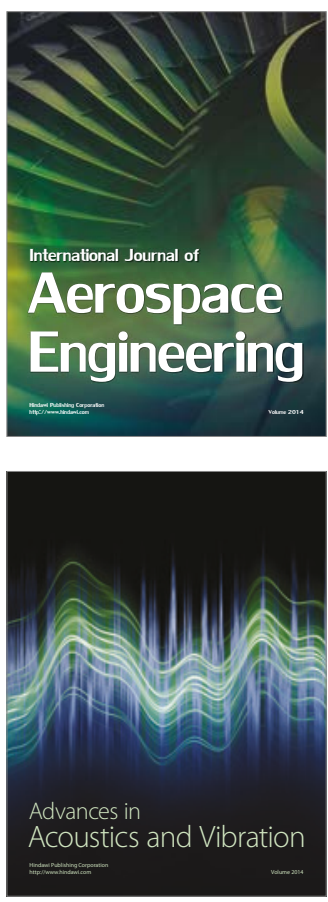

Sensor Networks 